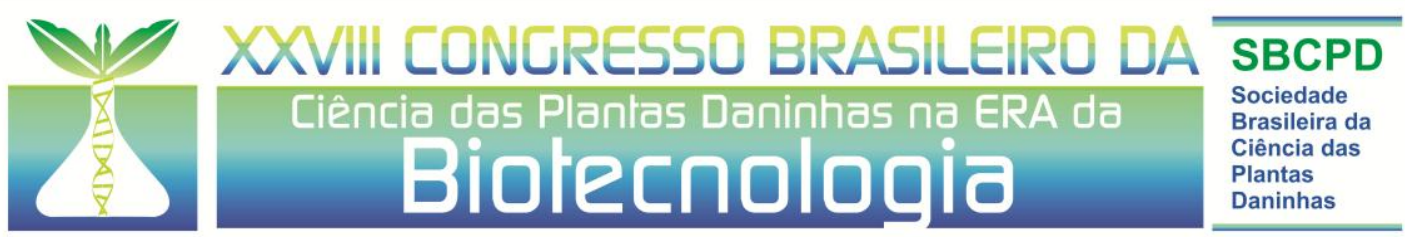

\title{
EFEITO DE CULTURAS ANTECESSORAS À CANA-DE-AÇUCAR NA COMPOSIÇÃO FLORÍSTICA DE PLANTAS DANINHAS
}

\author{
MASCARENHAS, M.H.T. (EPAMIG Centro Oeste, Prudente de Morais/MG, \\ mhtabimm@epamig.br); LARA, J.F.R. (EPAMIG Centro Oeste, Prudente de Morais/MG, \\ joselara@epamig.br,); MACEDO, G.A.R. (EPAMIG Centro Oeste, Prudente de Morais/MG, \\ geraldomacedol@epamig.br); VIANA, M.C.M. (EPAMIG Centro Oeste, Prudente de \\ Morais/MG, mcv@epamig.br; KARAM, D. (Embrapa Milho e Sorgo, Sete Lagoas/MG, \\ karam@cnpms.embrapa.br)
}

RESUMO - O estudo trata da identificação da composição florística de plantas daninhas em áreas de produção de cana-de-açúcar no município de Felixlândia, MG, em resposta a cultivos antecessores ao plantio desta cultura e ao período do ano. $O$ experimento foi conduzido na Fazenda Experimental da EPAMIG, no delineamento de blocos ao acaso, com seis tratamentos e quatro repetições, com a variedade SP81-3250. Os tratamentos foram os cultivos antecessores ao plantio da cana-de-açúcar: milheto, Crotalaria juncea, mucuna preta, guandu anão e soja, acrescido de uma testemunha (pastagem degradada de Brachiaria decumbens). Foi avaliada a composição florística nas quatro estações do ano. Foram identificadas 23 espécies de plantas daninhas, distribuídas em 18 gêneros e em 13 famílias. As famílias mais representativas foram as Leguminosae e Solanaceae, com quatro espécies, seguidas por Malvaceae, com três espécies e Convolvulaceae e Rubiaceae com duas espécies. $B$. decumbens foi encontrada em todos os diferentes sistemas de plantio da cana-de-açúcar nos períodos de inverno e primavera. As diferenças encontradas na composição florística tanto em relação ao cultivo antecessor utilizado como às épocas avaliadas se tornam relevantes para o planejamento do manejo adequado das plantas daninhas na cultura da cana.

Palavras-chave: Sacharum spp., cultivos antecessores, plantas daninhas

\section{INTRODUÇÃO}

Estima-se que nos próximos cinco a 10 anos a produção de álcool brasileira deverá dobrar, tendo em vista a demanda por álcool combustível no mercado interno e externo. Para atender a crescente demanda a expansão da cultura deverá ocorrer de forma acelerada na região do Brasil central, em áreas de cerrado ainda não cultivadas com canade-açúcar, principalmente sob pastagens degradadas. 
O sucesso da cultura da cana-de-açúcar em áreas degradadas de pastagens de cerrado poderá ocorrer com maior probabilidade se for adotado o princípio da integração/sucessão de culturas, com adaptações e ajustes para a esta cultura, levando-se em consideração o nível tecnológico em que a mesma é explorada.

A prática da adubação verde com leguminosas já é utilizada na reforma de canaviais. Cultura como o milheto também pode ser utilizado como antecessora ao plantio da cana, pois já é reconhecido pela capacidade de extração de nutrientes e liberação gradativa no solo, através de sua palhada, (Netto \& Bonamigo, 2005). Com base nestas informações torna-se importante avaliar a adubação verde e culturas para grão num processo de recuperação de áreas de pastagens degradadas de Brachiaria decumbens no cerrado, visando promover melhoria no ambiente de produção para implantação de canaviais.

Objetivou-se com este trabalho identificar a composição florística de plantas daninhas em áreas de produção de cana-de-açúcar, em resposta a cultivos antecessores ao plantio da cultura e ao período do ano.

\section{MATERIAL E MÉTODOS}

O experimento foi conduzido na Fazenda Experimental de Felixlândia da EPAMIG, no município de Felixlândia-MG. Foi adotado o delineamento experimental de blocos ao acaso, com seis tratamentos e quatro repetições. Os tratamentos foram os cultivos antecessores ao plantio da cana: milheto, Crotalaria juncea, mucuna preta, guandu anão e soja, acrescido de uma testemunha (pastagem degradada de $B$. decumbens), implantados em novembro. A área total da parcela foi de $378 \mathrm{~m}^{2}(10,5 \mathrm{~m} \times 36 \mathrm{~m})$, com área total do experimento de $9.072 \mathrm{~m}^{2}$.

Três meses após o plantio, fez-se a avaliação da produção de fitomassa dos adubos verdes e da soja e em seguida os mesmos foram incorporados ao solo. Quinze dias após, foi realizado o plantio da variedade de cana SP81-3250 em sucessão aos adubos verdes e soja nas parcelas que constaram de sete linhas de $36 \mathrm{~m}$ de comprimento cada.

O levantamento das plantas invasoras foi realizado em toda a área experimental, em setembro de 2009, antes da implantação das culturas antecessoras e o experimento foi instalado nessa mesma área.

Após a implantação do ensaio, procedeu-se ao levantamento das plantas invasoras, em quatro épocas distintas: aos 60, 120, 210 e 300 dias após o plantio das culturas, correspondendo, respectivamente, à infestação de verão (janeiro), de outono (março), de inverno (junho) e de primavera (setembro). Para identificar as espécies de plantas invasoras e o número de indivíduos, foi arremessado um quadro de $1 \mathrm{~m}^{2}$ em cada parcela, por quatro vezes, perfazendo uma área amostrada de $16 \mathrm{~m}^{2} /$ tratamento. 


\section{RESULTADOS E DISCUSSÃO}

No levantamento realizado na área de pastagem degradada de Brachiaria decumbens em setembro de 2009, antes da implantação das culturas de sucessão, foram identificadas seis espécies pertencentes a três famílias botânicas: Desmodium incanum DC. Papilionoideae (carrapicho-beiço-de-boi); Sida glaziovii K. Schum. - Malvaceae (guanxumabranca); Sida rhombifolia L. - Malvaceae (guanxuma); Solanum americanum Mill. Solanaceae (maria-pretinha); Solanum lycocarpam St. Hil. - Solanaceae (lobeira) e Solanum palinacanthum Dunal - Solanaceae (arrebenta-cavalo). A família Solanaceae, apresentou o maior número de espécies, seguida da Malvaceae.

Após o plantio da cana-de-açúcar, foi feito o levantamento das plantas daninhas, em quatro épocas distintas, correspondendo, respectivamente, à infestação de verão (V), de outono (O), de inverno (I) e de primavera (P). Foram identificadas 23 espécies de plantas daninhas, distribuídas em 18 gêneros e em 13 famílias. As famílias mais representativas foram as Leguminosae e Solanaceae, com quatro espécies, seguidas por Malvaceae, com três espécies, e Convolvulaceae e Rubiaceae com duas espécies (Tabela 1).

Tabela 1 - Relação das espécies de plantas daninhas identificadas no verão, outono, inverno e primavera nos diferentes sistemas de plantio da cana-de-açúcar. Felixlândia-MG, 2010.

\begin{tabular}{|c|c|c|c|}
\hline Família & Espécie & Nome comum & $\begin{array}{l}\text { Estações do ano }{ }^{1} / \\
\text { Cultura antecessora }^{2}\end{array}$ \\
\hline Amaranthaceae & $\begin{array}{ll}\text { Amaranthus } & \text { hybridus var. } \\
\text { patulus (Betol.) Thell } & \end{array}$ & caruru-branco & $\begin{array}{l}\mathrm{V} / \\
\mathrm{O} / \mathrm{G} \\
\mathrm{I} / \\
\mathrm{P} / T ; M P\end{array}$ \\
\hline Commelinaceae & Commelina benghalensis L. & trapoeraba & $\begin{array}{l}\text { V/T;M;C;MP;G;S } \\
\mathrm{O} / \\
\mathrm{I} / \\
\mathrm{P} /\end{array}$ \\
\hline $\begin{array}{l}\text { Compositae } \\
\text { (Asteraceae) }\end{array}$ & $\begin{array}{l}\text { Acanthospermum australe } \\
\text { (Loefl.) Kuntze }\end{array}$ & carrapicho-rasteiro & $\begin{array}{l}\text { V/ T;M;C;MP;G;S } \\
\text { O/ T;M;C;MP;G;S } \\
\text { I/ } \\
\text { P/ T;M;C;MP; G;S }\end{array}$ \\
\hline \multirow[t]{2}{*}{ Convolvulaceae } & $\begin{array}{l}\text { Ipomoea acuminata Roem. et } \\
\text { Sch. }\end{array}$ & jitirana & $\begin{array}{l}\text { V/T;M;C;MP; G; S; } \\
\text { O/T } \\
\text { // } \\
\mathrm{P} /\end{array}$ \\
\hline & $\begin{array}{l}\text { Ipomoea grandifolia (Dammer) } \\
\text { O' Donell }\end{array}$ & corda-de-viola & $\begin{array}{l}\text { V/ T;M;C;MP;G;S } \\
\text { O/ T;M;C;G;S } \\
\text { I/ } \\
\mathrm{P} /\end{array}$ \\
\hline Cucurbitaceae & Cucumis anguria $\mathrm{L}$. & maxixi & $\begin{array}{l}\mathrm{V} / \\
\mathrm{O} / \mathrm{G} \\
\mathrm{V} / \\
\mathrm{P} /\end{array}$ \\
\hline Euphorbiaceae & Caperonia palustris (L.) St. Hil. & castanheira-do-brejo & $\begin{array}{l}\mathrm{V} / \\
\mathrm{O} / T ; M ; M P ; G ; S \\
\mathrm{I} / \\
\mathrm{P} /\end{array}$ \\
\hline Gramínea (Poaceae) & Brachiaria decumbens Stapf & capim-braquiária & $\begin{array}{l}\text { V/M;MP;S } \\
\text { O/ T;C;G;S } \\
\text { I/ T;M;C;MP;G;S } \\
\text { P/ T;M;C;MP;G;S }\end{array}$ \\
\hline Labiatae & Hyptis lophanta Mart. ex Benth & catirina & $\mathrm{V} /$ \\
\hline
\end{tabular}




\begin{tabular}{|c|c|c|c|}
\hline & & & $\begin{array}{l}\mathrm{O} / T ; M ; C ; M P ; G ; S \\
\text { I/ } \\
\mathrm{P} / T ; M P\end{array}$ \\
\hline $\begin{array}{l}\text { Leguminosae } \\
\text { (Caesalpinoideae) }\end{array}$ & $\begin{array}{l}\text { Senna obtusufolia (L) H.S. Irvin } \\
\text { \& Barneby }\end{array}$ & fedegoso & $\begin{array}{l}\text { V/ T;C;MP;G;S } \\
\mathrm{O} / \mathrm{T} ; M ; C ; M P ; G ; S \\
\mathrm{I} / \\
\mathrm{P} /\end{array}$ \\
\hline $\begin{array}{l}\text { Leguminosae } \\
\text { (Mimosoideae) }\end{array}$ & Mimosa pudica L. & malícia-de-mulher & $\begin{array}{l}\text { V/S } \\
\text { O/ T;M;C;MP;S } \\
\text { I/ } \\
\mathrm{P} /\end{array}$ \\
\hline \multirow[t]{2}{*}{$\begin{array}{l}\text { Leguminosae } \\
\text { (Papilionoideae) }\end{array}$} & Desmodium incanum DC. & carrapicho-beiço-de-boi & $\begin{array}{l}\mathrm{V} / T ; G \\
\mathrm{O} / \\
\mathrm{l} / \\
\mathrm{P} /\end{array}$ \\
\hline & $\begin{array}{l}\text { Macroptilum lathyroides (L.) } \\
\text { Urb. }\end{array}$ & feijão-de-rôla & $\begin{array}{l}\mathrm{V} / \\
\mathrm{O} \\
\mathrm{I} / \\
\mathrm{P} / \mathrm{S}\end{array}$ \\
\hline \multirow[t]{3}{*}{ Malvaceae } & Sida glaziovii K. Schum. & guanxuma-branca & $\begin{array}{l}\text { V/ T;M;MP;G;S } \\
\mathrm{O} / \mathrm{T} ; M ; C ; M P ; G ; S \\
\mathrm{I} / \\
\mathrm{P} / \mathrm{T} ; \mathrm{C} ; \mathrm{MP} ; \mathrm{G} ; \mathrm{S}\end{array}$ \\
\hline & Sida rhombifolia L. & guanxuma & $\begin{array}{l}\mathrm{V} / T ; M ; M P ; G ; S \\
\mathrm{O} / \\
\mathrm{l} / \\
\mathrm{P} / \mathrm{M} ;\end{array}$ \\
\hline & Sida urens L. & guanxuma & $\begin{array}{l}\text { V/ T;M;MP;G;S } \\
\mathrm{O} / \\
\mathrm{l} / \\
\mathrm{P} / T ; C\end{array}$ \\
\hline \multirow[t]{2}{*}{ Rubiaceae } & Richardia brasiliensis Gomes & poaia-branca & $\begin{array}{l}\text { V/ T;M;C;MP; G;S } \\
\mathrm{O} / T ; M ; C ; G ; S \\
\text { I/ } \\
\mathrm{P} / M P\end{array}$ \\
\hline & Spermacoce latifolia Aubl. & erva-quente & $\begin{array}{l}\mathrm{V} / \mathrm{S} \\
\mathrm{O} / \\
\mathrm{l} / \\
\mathrm{P} /\end{array}$ \\
\hline \multirow[t]{4}{*}{ Solanaceae } & Nicandra physaloides (L.) Pers & joá-de-capote & $\begin{array}{l}\mathrm{V} / T ; M ; M P ; G ; S \\
\mathrm{O} / \\
\mathrm{I} / \\
\mathrm{P} /\end{array}$ \\
\hline & Physalis angulata L. & joá-de-capote & $\begin{array}{l}\mathrm{V} / \\
\mathrm{O} / \\
\mathrm{I} / \\
\mathrm{P} / \mathrm{MP}\end{array}$ \\
\hline & Solanum americanum Mill. & maria-pretinha & $\begin{array}{l}\mathrm{V} / \\
\mathrm{O} / \\
\mathrm{I} / \\
\mathrm{P} / M P\end{array}$ \\
\hline & Solanum palinacanthum Dunal & arrebenta-cavalo & $\begin{array}{l}\mathrm{V} / \mathrm{G} \\
\mathrm{O} / \\
\mathrm{l} / \\
\mathrm{P} / \mathrm{T} ; M ; C ; M P ; G ; S\end{array}$ \\
\hline Tiliaceae & Corchorus hirtus L. & vassoura & $\begin{array}{l}\mathrm{V} / \\
\mathrm{O} / T ; M ; M P ; G ; S \\
\mathrm{I} / \\
\mathrm{P} / T ; C ; \mathrm{G}\end{array}$ \\
\hline
\end{tabular}

${ }^{1}$ Estações do ano: Verão (V); Outono (O); Inverno (I), Primavera (P)

${ }^{2}$ Cultura antecessora: Testemunha (T); Milheto (M); Crotalaria C; Mucuna Preta(MP); Guandu (G); Soja (S)

Houve diferença na composição florística na área em estudo tanto em relação ao cultivo antecessor utilizado, como nas épocas avaliadas (Tabela 1). 
Nos períodos de inverno e primavera a $B$. decumbens foi encontrada em todos os diferentes sistemas de plantio da cana-de-açúcar, e foi a única espécie presente na área no período de inverno (Tabela 1). Segundo Kuva et al. (2003), as espécies de plantas daninhas pertencentes ao gênero Brachiaria apresentam elevada habilidade competitiva com a canade-açúcar. Estes autores observaram correlação negativa entre a produção de massa seca de $B$. brizantha e a produtividade de colmos de cana-de-açúcar. A produtividade dos colmos foi reduzida com o aumento da população $B$. brizantha apresentando redução de até $60 \mathrm{t}$ ha $^{-1}$, quando nas maiores infestações desta gramínea (Galon et al., 2011).

Nos levantamentos realizados no verão (V), nas parcelas onde a cultura antecessora foi o guandu anão $(G)$ e na primavera $(P)$, nas parcelas testemunha $(T)$, milheto $(M)$, mucuna preta (MP), guandu (G) e soja (S) foi encontrada a espécie Solanum palinacanthum, popularmente conhecida como arrebenta-cavalo. O arrebenta-cavalo é uma planta considerada tóxica para bovinos, devendo ser erradicada da área (Lorenzi, 2000).

\section{CONCLUSÕES}

B. decumbens foi encontrada em todos os diferentes sistemas de plantio da cana-deaçúcar nos períodos de inverno e primavera, e foi a única espécie presente na área no período de inverno.

As diferenças encontradas na composição florística tanto em relação ao cultivo antecessor utilizado, como às épocas avaliadas se tornam relevantes para o planejamento do manejo adequado das plantas daninhas na cultura da cana.

\section{AGRADECIMENTOS}

À Fundação de Amparo à Pesquisa do Estado de Minas Gerais (FAPEMIG) pelo financiamento do projeto de pesquisa e bolsas de produtividade científica (BIPDT).

\section{REFERÊNCIAS BIBLIOGRÁFICAS}

GALON, L. et al. Interferência da Brachiaria brizantha nas características morfológicas da cana-de-açúcar. Planta Daninha, v.29, p.1029-1036, 2011. Número Especial.

KUVA, M. A. et al. Período de interferência de plantas daninhas na cultura da cana-deaçúcar. III - capim-braquiária (Brachiaria decumbens) e capim-colonião (Panicum maximum). Planta Daninha, v.21, n.1, p.37-44, 2003.

LORENZI, H. Plantas daninhas do Brasil: terrestres, aquática, parasitas e tóxicas. Harri Lorenzi. 3. ed. Nova Odessa, SP; Instituto Plantarum. 2000. 608p.

NETTO, D. A. M.; BONAMIGO, L. A. Milheto: características da espécie e usos. In: Milheto: tecnologias de produção e agronegócio. NETTO, D. A. M e DURÃES, F. O. M.(Ed.), Brasília, DF: Embrapa Informação Tecnológica, 2005. p.21-36. 